\title{
CONGENITAL ADENOMATOID MALFORMATION OF LUNG WITH PNEUMOTHORAX
}

\author{
BY \\ ROY G. SPECTOR, ALBERT E. CLAIREAUX and E. ROHAN WILLIAMS \\ From the Bernhard Baron Memorial Research Laboratories, Queen Charlotte's Maternity Hospital, London \\ and The Institute of Obstetrics and Gynaecology, University of London
}

(RECEIVED FOR PUBLICATION DECEMBER 21, 1959)

\begin{abstract}
Although hamartomas of the lungs are not common, they cannot be considered as pathological curiosities. Several cases have been reported in recent years (Harris and Schattenberg, 1942; Jones, 1949; Thomas, 1949; Timossi, 1955; Lima, Zerbini and Bittencourt, 1955; Gottschalk and Abramson, 1957; Galvez Fermin, 1958; Cornéa, Dichter, Gamentay and Mindru, 1959; Bain, 1959). One variety of hamartoma of the lung, namely congenital cystic disease of the lung, has received an increasing amount of attention since Koontz (1925) collected his large series of cases. Ch'in and Tang (1949) coined the expression 'congenital adenomatoid malformation' for this condition. They found descriptions of 10 cases in the literature up to that time and added one case of their own.
\end{abstract}

A comprehensive review of the literature was made by Craig, Kirkpatrick and Neuhauser (1956). They mentioned the 11 cases in Ch'in and Tang's paper, 11 other cases and added four of their own. Coffee (1956) also reviewed the position at that time. Since then, one case by Goodyear and Shillitoe (1959) and four cases by Herrmann, Jewett and Galletti (1959) have been reported. These workers distinguished between those cases which present clinically in early neonatal life with cyanosis and those which present later with signs of infection. This report is concerned with a case of congenital cystic disease of the lung which was accompanied by hypoplasia of the entire remaining lung tissue and in which a tension pneumothorax occurred following attempts at resuscitation.

\section{Case Report}

Clinical History. The mother was 26 years of age and had had one previous normal pregnancy. Her general health was good. During pregnancy the only abnormality detected was hydramnios at about 27 weeks.

The onset of labour was spontaneous and occurred at the end of the 28th week. The duration of the first stage was one hour and of the second stage 20 minutes. The presentation was vertex and delivery was spontaneous.

At birth the child was oedematous, cyanosed and apnoeic. Attempts at resuscitation were followed by only two or three shallow gasps.

\section{Radiological Investigation.}

Antenatal Examination. The patient was referred for radiological examination (to exclude foetal abnormality or twin pregnancy) on September 22, 1959; the height of the fundus corresponded to that normally expected at 34-35 weeks; by dates, the maturity was 27 weeks. One foetus was present in a vertex L.O.A. position, with evident hydramnios in considerable degree. The foetal stature corresponded to that expected for a maturity of 27-28 weeks. The attitude of the foetus, both of the trunk and the limbs, was reminiscent of that often found in hydrops foetalis and at least suggested the presence of some foetal abdominal distension.

Postnatal Examination. Radiographs (Figs. 1 and 2) were taken of the whole infant shortly after its death which occurred at 10 minutes after birth. It was evident that air had been both swallowed and inhaled. There was slight distension of the abdomen but this was not due to intestinal gas. The thorax presented most unusual appearances. There was a right pneumothorax with a complex loculated appearance peripherally. The margin of this pneumothorax extended well across to the left of the mid-line and no pulmonary aeration was observed on either side. The volume occupied by the left lung was evidently much reduced. The cardiac outline could not be separately discerned. Thus the appearances bore some resemblance to those found in a tension pneumothorax on the right side, but the opacity due to the compressed lung was much greater than would be expected.

Necropsy. This revealed a premature male infant weighing $1,550 \mathrm{~g}$. whose crown-rump length was $28 \mathrm{~cm}$. and crown-heel length was $39 \mathrm{~cm}$. There was marked oedema of the arms and back and the abdomen was distended. There were no other abnormalities seen on external examination. The pleural sacs contained no 


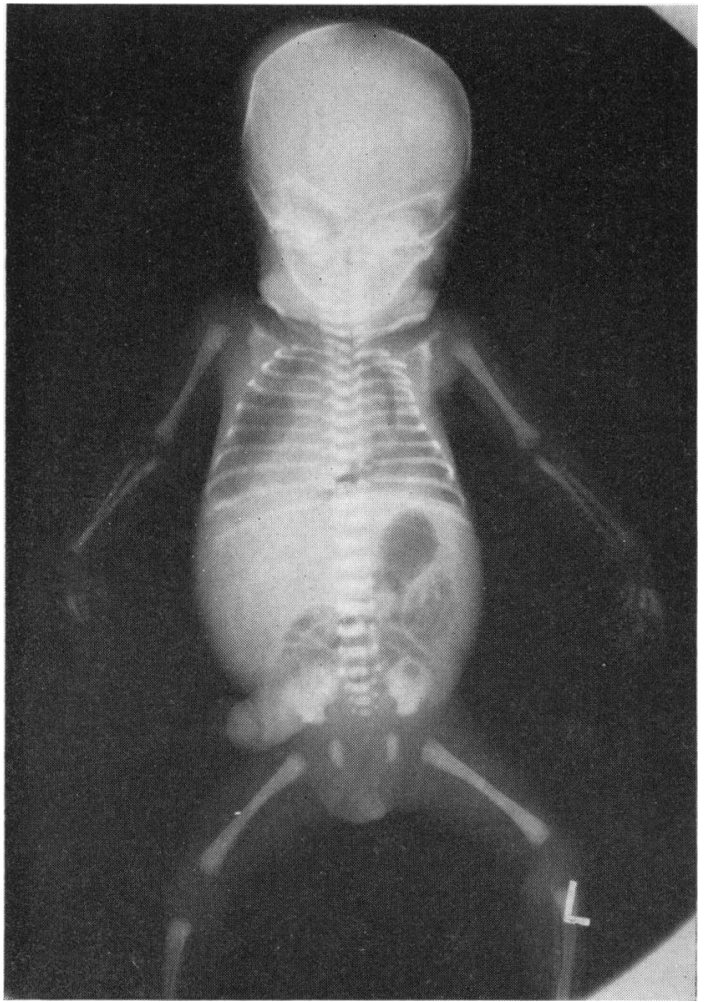

FIG. 1.-Radiograph. Antero-posterior view showing right-sided pneumothorax. There is a cystic space containing air in the mass in the right lung. The mediastinum is displaced to the left.

excess fluid. There was a pneumothorax on the right side which was under tension. The pleurae were glistening. The larynx, trachea and main bronchi were normal. A large, firm, pink, nodular mass involved the upper lobe of the right lung (Fig. 3). On slicing, several cystic cavities were opened (Fig. 4). The mass was approximately three times the usual size of the right upper lobe. A probe could be passed from the right upper lobe bronchus into one of the cysts. The malformation was so large that it had herniated across the midline. The left lung and the middle and lower lobes of the right lung were hypoplastic. The pericardial sac contained no excess fluid. The heart was of the expected size and there were no congenital abnormalities of either the heart or great vessels but the organ was displaced to the left. There was a moderate excess of clear, yellow fluid in the peritoneal sac. The tongue, pharynx, oesophagus, stomach and intestines were normal. The liver was of the expected size and appeared macroscopically normal. The bile passages were patent. The falx cerebri and tentorium cerebelli were intact. There was a small amount of blood diffusely spread in the subarachnoid space over both cerebral hemispheres and over the cerebellum. The brain and choroid plexuses were congested. The adrenals (each $1.5 \mathrm{~g}$.), pituitary,

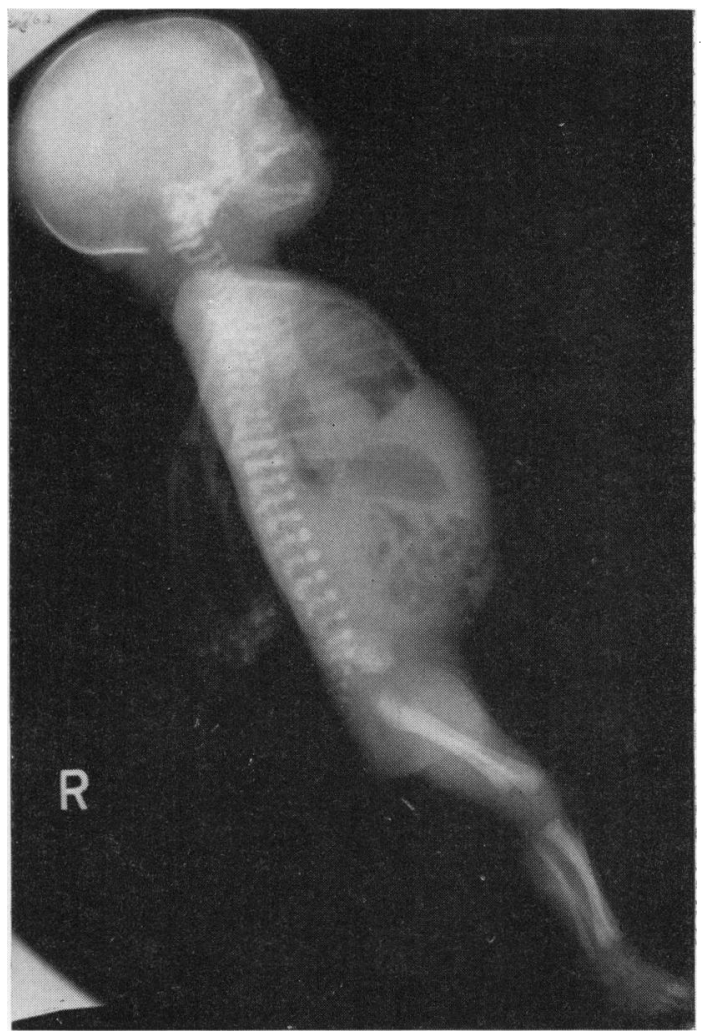

FIG. 2.-Radiograph. Lateral view. Air can be seen in the small intestine.

thymus and thyroid glands were normal. The kidneys (each $8 \mathrm{~g}$.) showed foetal lobulation. The ureters, bladder and external genitalia were normal. The placenta weighed $370 \mathrm{~g}$. and measured $17 \times 14 \mathrm{~cm}$. The placental/foetal weight ratio was $1: 4 \cdot 1$. There was a velamentous insertion of the cord. The membranes were complete. The placenta was not oedematous and appeared normal on slicing.

\section{Histology.}

UPPER LOBE OF RIGHT LUNG. The pleura showed little change. The mass consisted of innumerable small acini lined by a low cuboidal epithelium (Fig. 5). They were separated from one another by a loose connective tissue stroma which contained elastic fibres. Some larger cystic spaces lined by columnar epithelium were also present. These were surrounded by smooth muscle 1-3 layers thick. These structures had the appearance of terminal bronchioles and some showed very marked dilatation (Fig. 6). There was no evidence of cartilage formation in the wall of any of the bronchial-like structures and no glands were present in their submucosa. In a number of areas there were collections of several acini lined by tall, columnar, mucus-secreting epithelium (Fig. 7). The material in the lumen of these 


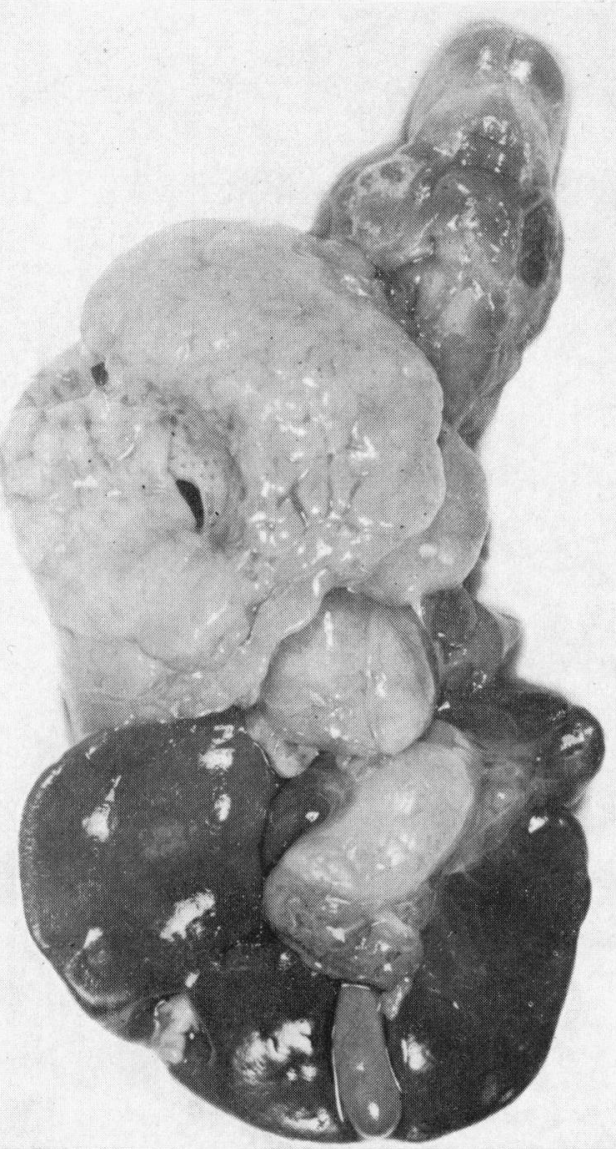

FIG. 3.-Large mass replacing the upper lobes of the right lung. A ruptured cyst is seen in the centre. The left lung is extremely hypoplastic.

structures gave a strongly positive reaction when stained by the periodic acid-schiff technique. The appearance of the mass was consistent with a diagnosis of congenital adenomatoid malformation. There was no subdivision of the mass into lobules. There was a sharp demarcation at the lower border of the mass between malformed tissue and adjoining hypoplastic lung (Fig. 5). A narrow connective tissue septum appeared to separate the one from the other.

Middle AND Lower LoBe of Right Lung. The pleura was healthy. The lobes showed marked hypoplasia and were unexpanded. The bronchi, bronchioles, alveolar ducts and alveoli showed no structural lesion.

LEFT LUNG. This lung was also extremely hypoplastic. The bronchial structure appeared to be normal.

No lesion was found on histological examination of the other organs.

\section{Discussion}

Willis (1958) defined hamartomas as tumour-like, but primarily non-neoplastic malformations or

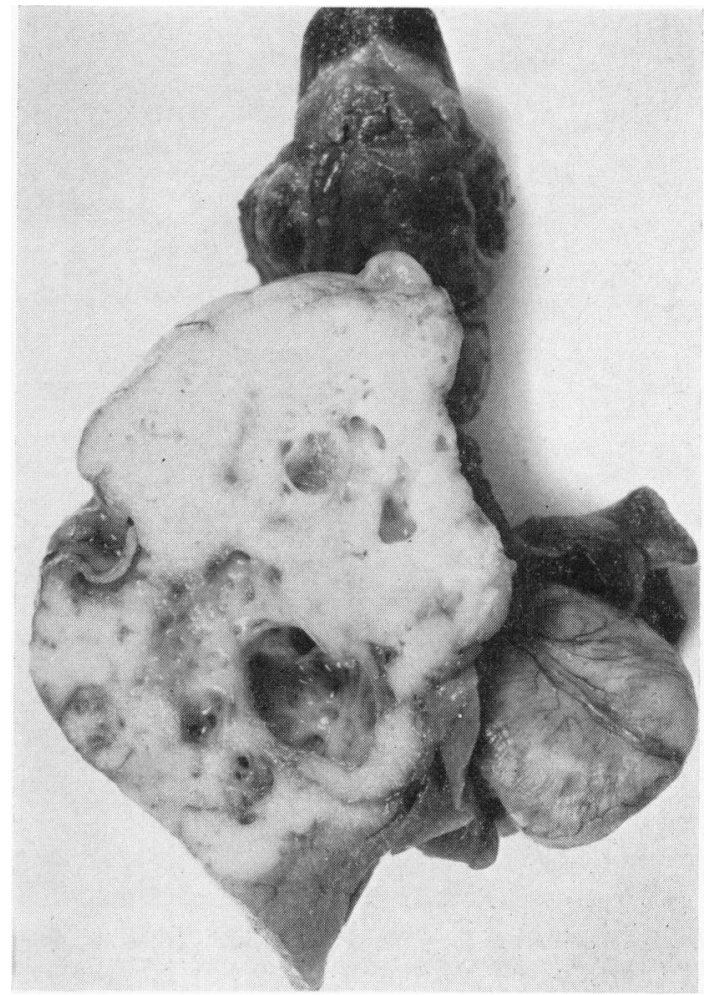

FIG. 4.-Section of the mass showing several large cysts. The middle and lower lobes of the right lung are hypoplastic.

errors of tissue development. characterized by abnormal mixture of tissues indigenous to the part with excess of one or more of these. On these grounds he does not consider 'chondromatous hamartomas' of the lung to be malformations but true tumours. Nevertheless, cartilage-containing

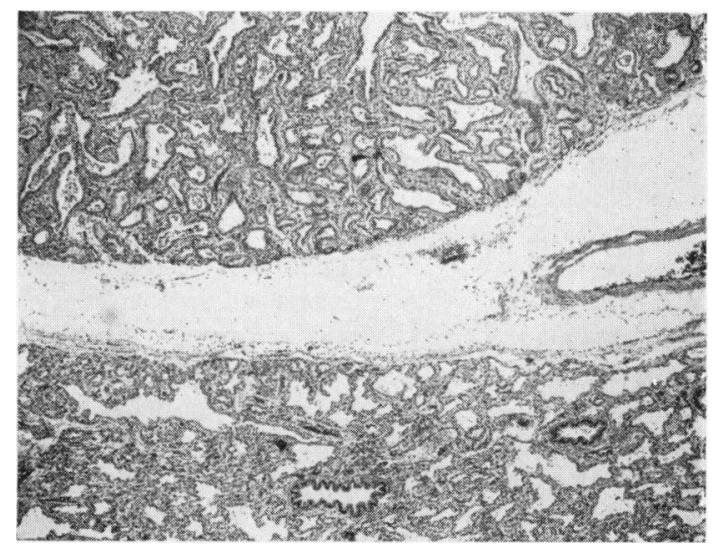

FIG. 5.-Showing adjacent areas of hamartoma (above) and hypoplastic lung. H. and E. $\times 26$. 


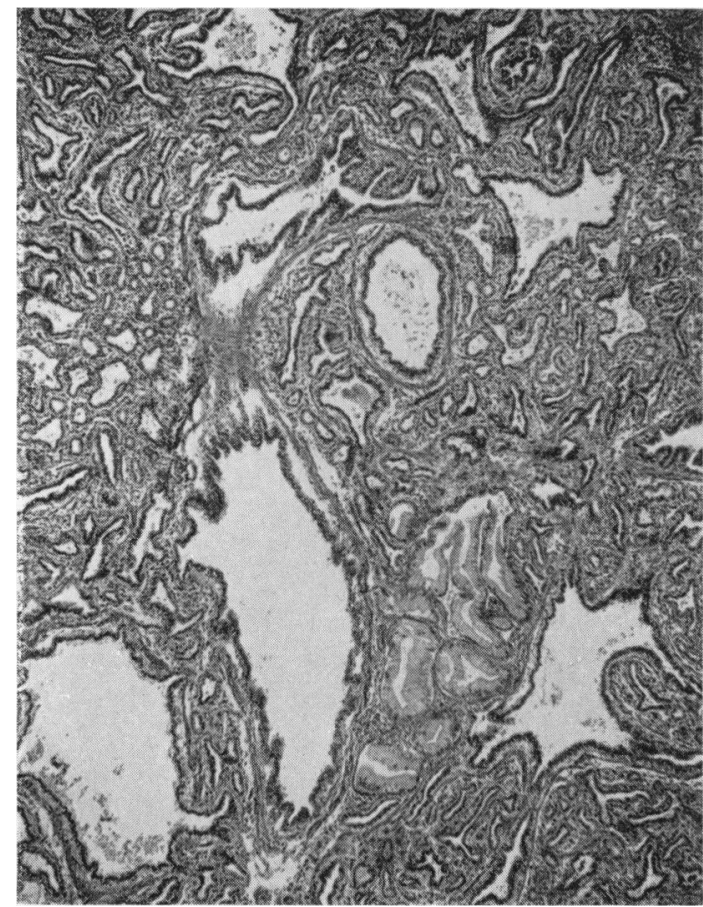

Fig. 6.-Malformation showing large cystic spaces lined by respiratory epithelium and surrounded by some layers of smooth muscle. $A$ focus of mucus secreting epithelium is present. $\quad H$. and E. $\times 48$.

hamartomas are occasionally found in the lungs of infants. Jones (1949) described such a case in which there was an admixture of foetal lung tissue, cartilage and fibrous tissue which had replaced part of one lung of an infant. The appearances were not those of a neoplasm but of a malformation of lung tissue, and the author suggested that this was a true cartilage-containing hamartoma. As well as the more solid type of hamartoma such as described by Harris and Schattenberg (1942), Willis includes congenital cystic disease in this class of disorders of the lungs. Klosk, Bernstein and Parsonnet (1946) define cystic disease of the lung as 'any condition in which the lung parenchyma is replaced by sharply defined cavities containing fluid or air'. These authors divide this disease into the variety which exhibits solitary large cysts and that characterized by multiple cysts. Herrmann et al. (1959) describe an acquired type. The cysts in the congenital form of the disease are lined by pseudo-stratified ciliated columnar epithelium or respiratory cuboidal epithelium. In the more common form of cystic disease of the lung, however, cartilage is present in the bronchial wall. It is notably absent in adenomatoid malformation.

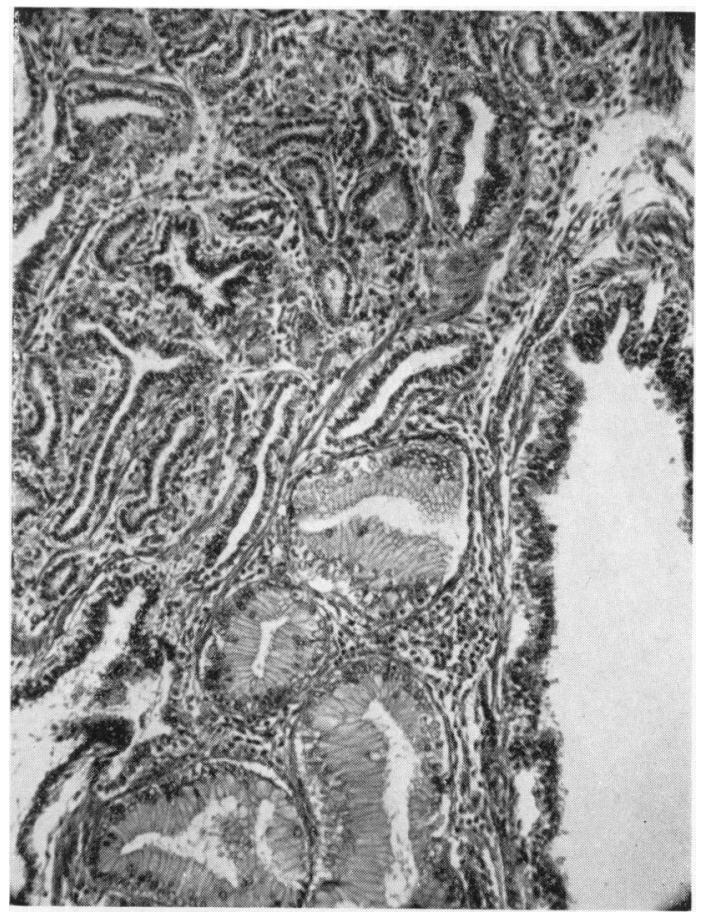

FIG. 7.-High power view of part of field in Fig. 3 showing detail of mucus secreting tissue. H. and E. $\times 103$.

Histological examination of the lung in this case showed small cystic spaces lined by a low columnar epithelium of the respiratory variety in most areas. Other parts of the hamartoma contained spaces lined by cuboidal and tall columnar epithelium. Levine (1950) postulates that this form of hamartoma arises by pinching off of portions of the main lung buds and their derivatives in the second half of intrauterine life. Some of these portions of bronchial tissue may completely separate from the bronchial tree and continue to secrete fluid which will distend the cysts. Other portions do not completely separate but maintain a narrow communication with the bronchi. In our case, we were able to pass a probe from a main bronchus into one of the larger cysts. This apparently supports Levine's suggestion as to their mode of origin. Herrmann et al. (1959) mention, in addition, a second possible mode of origin, namely a disturbance occurring in the fourth foetal week. At this time two septa divide the foregut into an anterior and posterior part. If cells from this region detach themselves at about this period, then bronchial or gastric cysts would arise. The occurrence of cystic spaces lined by mucus secreting epithelium 
has been noted by previous authors (Ch'in and Tang, 1949; Koboth, 1936) and this suggests that the anomaly may have its origin during the fourth foetal week. Craig et al. (1956), however, regard these as aberrant forms of bronchial mucous glands. Conway (1951) believes congenital cystic disease of the lung is the result of some unknown process which interferes with canalization at some point proximal to the termination of the lung bud. Distal to this point canalization begins again producing an isolated canalized segment lined by normal bronchial mucosa. In adenomatoid hyperplasia there is a great increase in the number of structures which have the appearance of terminal bronchioles. The smaller spaces lined by cuboidal epithelium probably represent incompletely formed alveolar ducts.

At necropsy the hamartoma is usually found to increase both the size and weight of the affected lung (the increase in bulk often causing herniation of the lung across the midline with mediastinal displacement) both of which occurred in the present case. In most cases, only one lobe of the lung is affected; indeed, we have found records of only two cases in which an entire lung was involved (Wolman, 1930; Goodyear and Shillitoe, 1959). We have found no preference for the right or left lung and for upper, lower or middle lobes. On slicing the abnormal tissue mass, cysts of varying size are usually seen lying in firm, pale, macroscopically homogeneous tissue. Our case showed relatively few cysts. We found no cartilage in the affected part of the lung and this favours the theory of a valve-like mechanism by which air can enter the spaces of the hamartoma during inspiration but, because of lack of supporting tissue around the communicating channels with the bronchi, air is trapped during expiration. In this way the size of the malformation progressively increases after birth and the 'expanding lung syndrome' is produced. This causes not only displacement of the mediastinum but distortion of the venae cavae and maldevelopment of the contralateral lung. In our case, not only was there hypoplasia of the lung on the opposite side, but of the other lobes of the ipsilateral lung. As in previously reported cases we found no congenital abnormality in any other part of the body.

The diagnosis of this condition is not without difficulty, but, in the present case, foetal abnormality was first considered when hydramnios developed in the 27th week of pregnancy. This is a common feature of cystic disease of the lung, but is unique in that hydrops foetalis was diagnosed by a maternal pelvic radiograph during pregnancy. ,Ch'in and Tang (1949) and Gottschalk and Abramson (1957) suggest that the hydramnios is due to cardiovascular disturbance in the foetus following mediastinal and vena caval displacement by the tumour. This is postulated to produce an increase in systemic venous pressure resulting in not only hydrops foetalis but hydramnios. There seems to be little evidence that the oedema is the result of cardiac failure. Generalized anasarca is less common in foetuses with this malformation delivered at term or in infants who live for some time after birth (Craig et al., 1956).

Children suffering from this disease are usually premature; presumably the early labour results from hydramnios. Ch'in and Tang's series consisted mainly of premature and stillborn foetuses, and other cases reported up to 1943 were either stillborn or died in early neonatal life. The mother of our case went into labour at 28 weeks and spontaneously delivered a moderately oedematous and cyanosed infant. Oedema is not unusual in this condition (Grawitz, 1880; Ch'in and Tang, 1949; Craig et al., 1956) and, as mentioned above, is probably due to vena caval distortion. Thus hamartoma of the lung should be borne in mind in the differential diagnosis of cyanosis and oedema in a premature infant.

Tension pneumothorax may result from this malformation (Herrmann et al., 1959), although the vast majority of cases result from rupture of an emphysematous bulla on the surface of the lung or (in slightly older infants) staphylococcal bronchopneumonia. Our case was unusual in that rupture of an air-containing cyst had occurred following attempts at resuscitation.

The cases of Fischer, Tropea and Bailey (1943), of Graham and Singleton (1955), the four cases of Craig et al. (1956) and the four cases of Herrmann et al. (1959) were all diagnosed during life by radiological examination. This investigation should be performed in all cases in which pulmonary hamartoma is considered as a possible diagnosis.

In retrospect, it seems evident that the loculated appearance in the radiograph of our case was due to air in the superficial cystic parts of the tumour and that a marginal rupture had occurred leading to the pneumothorax. Whilst the limits of part of the tumour were surely outlined, it was not possible to differentiate between the tumour and the atelectatic right lung.

Treatment of this condition is removal of the affected tissue. As the child continues to breathe the cysts in the malformed lung increase in size and progressive displacement of the mediastinum with compression of the contralateral lung occurs. Thus early treatment is imperative, and this, in 
turn, depends on early radiological diagnosis of the disease. Our case was complicated by a tension pneumothorax and hypoplasia of all the lung tissue not involved in the hamartoma. The period of survival was insufficient to permit surgical intervention.

\section{Summary}

A case of hamartoma of the lung is described in an infant who survived for 10 minutes after delivery. The remaining lung tissue was hypoplastic. A tension pneumothorax was present on the same side as the lesion.

Foetal abnormality was suspected during pregnancy on account of hydramnios. Radiological examination revealed a hydropic foetus. At necropsy a large mass was found replacing the upper lobe of the right lung. On histological examination the mass was found to be composed of multiple small cysts and spaces lined by respiratory type epithelium.

The relationship between congenital cystic disease of the lung and true pulmonary neoplasm is discussed.

We are indebted to Mr. E. Clark of the Bernhard Baron Memorial Research Laboratories, Queen Charlotte's Hospital, for the photograph and photomicrographs.

\section{REFERENCES}

Bain, G. O. (1959). Congenital adenomatoid malformation of the lung. Dis. Chest, 36, 430 .

Ch'in, K. Y. and Tang, M. Y. (1949). Congenital adenomatoid malformation of one lobe of a lung with general anasarca. Arch. Path., 48, 221.
Coffee, H. L. (1956). Congenital lung cysts; a review of the literature and case report. J. med. Ass. Ga. 45, 199.

Conway, D. J. (1951). The origin of lung cysts in childhood Arch. Dis. Childh., 26, 504.

Cornéa, P., Dichter, I., Gamentay, E. and Mindru, M. (1959). Un cas d'hamertome pulmonaire. Sem. Hôp. Paris, 35, 1029.

Craig, J. M., Kirkpatrick, J. and Neuhauser, E. B. D. (1956). Congenital cystic adenomatoid malformation of the lung in infants. Amer. J. Roentgenol., 76, 516.

Fischer, C. C., Tropea, F., Jr. and Bailey, C. P. (1943). Congenital pulmonary cysts; report of an infant treated by lobectomy with pulmonary cysts; report 23, 219.

Galvez Fermin, N. (1958). Consideraciones sobre un caso de hamartoma del pulmon. Arch. cuban. Cancer., 17, 143.

Goodyear, J. E. and Shillitoe, A. J. (1959). Adenomatoid hamartoma of the lung in a newborn infant. J. clin. Path., 12, 172.

Gottschalk, W. and Abramson, D. (1957). Placental edema and fetal hydrops: a case of congenital cystic and adenomatoid malformation of the lung. Obstet. and Gynec. 10, 626.

Graham, G. G. and Singleton, J. W. (1955). Diffuse hamartoma of the upper lobe in infant: Report of successful surgical removal. Amer. J. Dis. Child., 89, 609.

Grawitz, P. (1880). Ueber angeborne Bronchiectasie. Virchows Arch. path. Anat., 82, 217.

Harris, W. H. and Schattenberg, H. J. (1942). Anlagen and rest tumors of the lung inclusive of 'mixed tumours' (Womack and Graham). Amer. J. Path., 18, 955.

Herrmann, J. W., Jewett, T. C., Jr. and Galletti, G. (1959). Bronchogenic cysts in infants and children. J. thorac. Surg., 37, 242.

Hückel, R. (1927). Beitsäge zur angeborenen Wabenlunge. Frankfurt. Z. Path., 35, 320.

Jones, C. J. (1949). Unusual hamartoma of the lung in a newborn infant. Arch. Path. (Chicago), 48, 150.

Klosk, E., Bernstein, A. and Parsonnet, A. E. (1946). Cystic disease of the lung. Ann. intern. Med., 24, 217

Koboth, I. (1936). Geschwulstartige Fehlbildungen eines Lungenlappens bei einer Frühgeburt. Frankfurt. Z. Path., 50, 10.

Koontz, A. R. (1925). Congenital cysts of the lung. Bull. Johns Hopk. Hosp., 37, 340.

Levine, R. M. (1950). Congenital cystic disease of the lung. Canad. med. Ass. J., 62, 181 .

Lima, M. L. M. T. de, Zerbini, E. J. and Bittencourt, D. (1955) Hamartomas do pulmâo. Rev. paul. Med., 47, 143.

Thomas, M. R. (1949). A cystic hamartoma of the lung in a newborn infant. J. Path. Bact., 61, 599.

Timossi, C. (1955). Su di un caso di amartoma polmonare. Arch. Radiol (Napoli), n.s. 4, 355.

Willis, R. A (1958). The Borderland of Embryology and Pathology. Butterworth, London.

Wolman, I. J. (1930). A case of congenital cystic lung in a stillborn fetus. Bull. Ayer. clin. Lab., 2, No. 12, p. 49. 